\title{
The effects of 4-nonylphenol contamination on livers of Tilapia fish (Oreochromus spilurs) in Jeddah
}

\author{
El-jawaher Abdulla Bin-Dohaish \\ Girls College of Science, University of King Abdul Aziz, Jeddah, Saudi Arabia.
}

\begin{abstract}
Alkylphenol polyethoxylates is a group of estrogenic compounds. Natural or synthetic types of these compounds react with the endocrine system by binding hormone receptors, resulting in interference with their action, which is why they are called endocrine disrupting chemicals. Among their hydrolytic products are nonylphenols (NP), which are considered pollutants of aquatic environments. The objective of this study was to evaluate the pathological alterations on liver tissue of fish exposed to these compounds for long durations, starting from beginning of life and during the period of sexual maturity. Tilapia fish were obtained from Abhur fish farms, reared in the laboratory in special basins, and divided into two groups. The first maternal group was untreated and their larvae were divided into three sub-groups: control; exposed to $15 \mu \mathrm{g} / \mathrm{L}$; and exposed to $30 \mu \mathrm{g} / \mathrm{L}$. The second maternal group was divided into 2 sub-groups: with larvae exposed to $15 \mu \mathrm{g} / \mathrm{L}$; and with their larvae exposed to $30 \mu \mathrm{g} / \mathrm{L}$. Larvae and mother exposed to different concentrations of NP (15 and $30 \mu \mathrm{g} / \mathrm{L})$ showed an increased accumulation of NP in both livers and muscles compared to the control group due to bioaccumulation. Tissue section examinations of the treated group ( $15 \mu \mathrm{g}$ NP / L) showed disruption of liver architecture, with lyses, loss of nuclei, necrosis, and fatty infiltration. The changes were more marked in tissues exposed to $(30 \mu \mathrm{g} \mathrm{NP} / \mathrm{L})$. Although this pollution was not lethal, its effect may be reflected in vital activities and in the economy.
\end{abstract}

Key words: nonylphenol, Tilapia fish ,liver, histology.

\section{INTRODUCTION}

Alkylphenol polyethoxylates are considered effective surfaceacting agents (Nimord and Benson, 1996). Many studies have indicated that these compounds have the ability to change or stop the normal physiological functions of organisms exposed to them, due to their estrogenic nature. Natural or synthetic types of these compounds react with the endocrine system by binding hormone receptors, resulting in interference with their action and metabolism, which is why they are called endocrine disrupting chemicals (EDCs) (Tyler et al., 1998). They are considered a great threat to living organisms in water environments and consequently to human beings (Jessica et al., 2006). These estrogen analogues are originally derived from many sources, such as paper, dyes, paints, detergents, and agricultural activity. They are drained into sewage systems and finally seep into ground waters (Johnson et al., 2005). Among these synthetic estrogens is 17 alpha ethinyl estradiol, which is of special concern because of its use as an oral contraceptive and its widespread presence in treated sewage water (Ying et al.,2002). It is also considered a dangerous compound because of its effectiveness in nanogram concentrations (Ascenzo et al., 2003). It was synthesized specifically to resist lyses and metabolic degradation in vivo (Kime, 1998). In vitro alkylphenol polyethoxylate compounds are susceptible to hydrolysis to ethoxylates with short bonds and derivatives of carboxylic acid. Finally, they are degraded to alkylphenols, (Nimrod and Benson, 1996), lipophilic and persistent metabolites (Ahel and Giger, 1993). Among these hydrolytic products are nonylphenols (NP) that are considered pollutants found in practically all aquatic environments. They have not only been found in sewage water, but also in surface water, sediments with concentrations ranging from nano to milligram quantities per liter (Talmage, 1994). EDCs compounds disrupt the endocrine system that regulates most responses in living organism. They include synthetic products like biphenol A, polychlorinated biphenol, dioxins, phtalates, pesticides, heavy metals, alkyphenols, polycyclic aromatic hydrocarbons, ethinylestradiol and estradiol. All these compounds, among others, seep from sewage water to aquatic environments (Ying et al., 2002;Ma et al., 2005). It is likely that there is an association between exposure to these compounds and changes observed in secondary sex characteristics of male and female fish (Bindohaish, 2008).

Many studies have demonstrated that alkylphenols have estrogenic effects that inhibit testicular growth in rainbow fish (Oncorhynchus mykiss), carp (Platichthys flesus), and flounder (Platihthys flesus). They also stimulate production of egg forming cells in immature Japanese medaka fish (Oryzias Latipes). In addition, they stimulate synthesis of one protein present in yolk vitellogenin. The latter is considered a sensitive biomarker for estrogen exposure (Gimeno et al., 1998).

Mathiessen et al. (1998) found that the effect of estrogen on fish was much wider than previously thought. The presence of these compounds in water and their consequent ingestion by living organisms became a major concern.

The aim of this study is to evaluate the pathological alterations on fish livers due to exposure to different concentrations of 4-nonylphenol compounds for long durations, starting from the beginning of life and during the period of sexual maturity, as well as comparing levels of alterations between fish from contaminated and noncontaminated mothers. 


\section{MATERIALS AND METHODS}

\section{Chemicals}

4-nonylphenol was purchased from Luborchemikalien sigmaAldrich, dissolved in ethanol, diluted to concentrations of 15 and $30 \mu \mathrm{g} / \mathrm{L}$ in basins prepared for rearing. Other basins with natural seawater were used for the control group.

Study site

The area of Abhur, close to the College for Marine Science, is considered an ideal region because it far from industrial areas. Specimens of water and sediments were collected in July 2008. Water (5 liters/region) was collected in polyethylene containers. Sediments (the top $15 \mathrm{~cm}$ ) were collected for analysis. The fish were handled in conformance with the Guiding Principles in the Care and Use of Laboratory Animals, endorsed by the American Physiological Society.

\section{Fish}

Tilapia fish (Oreochromus spilurs) were selected because they are easy to obtain and use in laboratory experiments. They are the most suitable species that can be reared in the Jeddah sea environment. In addition, they can live in a range of high levels of salt content, have a reproduction rate and are resistant to diseases and parasites.

The first group

Tilapia fish (weight: $16.25 \pm 0.43 \mathrm{~g}$. and length $8.5 \pm 0.48 \mathrm{~cm}$.) were obtained from fish farms in the Abhur area. They were reared in the laboratory in special basins from egg-laying, hatching and larvae formation, without treatment.

The larvae were collected and divided into three subgroups. Each group contained 50 fish:

1. The first sub-group was reared without treatment until maturity.

2. The second sub-group was exposed to $(15 \mu \mathrm{g} / \mathrm{L})$ nonylphenol.

3. The third was exposed to $(30 \mu \mathrm{g} / \mathrm{L})$ nonylphenol.

Specimens from young and mothers were obtained.

The second group

Tilapia fish (weight: $16.25 \pm 0.43$ g. and length: $8.5 \pm 0.48 \mathrm{~cm}$.) were obtained from fish farms in the Abhur area. They were reared in the laboratory in special basins, divided into two subgroups, each group containing 50 fish:

1. The first sub-group was exposed to $(15 \mu \mathrm{g} / \mathrm{L})$ nonylphenol.

2. The second was exposed to $(30 \mu \mathrm{g} / \mathrm{L})$ nonylphenol.

The experiment continued in the same conditions from egg-laying, hatching and larvae formation until maturity. Specimens from young and mother were obtained.

During the experiment, which extended from July until December 2008, fish were maintained under suitable light, temperature and feeding conditions. Basins were inspected daily to remove unconsumed food and excreta that could easily pollute the water. Waste pipelines and ventilation lines were routinely cleaned to remove dirt. The numbers of dead fish throughout the experiments were recorded.

Experimental studies

1. Histological examination

Fish were removed from the basins, dried on filter paper, dissected and livers were extracted. General morphological characteristics of the organ, such as color, size and texture, were registered. The organ was preserved in $10 \%$ formalin for 24 hrs. Livers were dehydrated, paraffinized and then cross-sectioned at 2-3 microns, followed by staining with hematoxylin and eosin for light microscopic examination.

2. Determination of bioaccumulation of nonylphenols in tissues

Concentrations of 4-nonylphenols were measured in livers and muscles. Specimens were dried, ground, and digested with nitric acid. The sediment $(1-5 \mathrm{~mm})$ was dissolved in one normal nitric acid, completed with deionized water, kept in clean bottles and the substance concentration was measured by atomic absorption spectroscopy.

\section{RESULTS}

\section{Water and sediment analysis}

Table (1) shows the mean concentrations of nonylphenol (Abhur area - Red Sea coast, Jeddah) in water $(4.65 \pm 2.61 \mu \mathrm{g} / \mathrm{L})$ and sediments $(32.33 \pm 3.21 \mu \mathrm{g} / \mathrm{g}$.) and this considered the natural concentration in the environment.

Bioaccumulation of 4-NP in selected organs

Table (2) demonstrates that:

1. concentrations of NP are higher in the livers $(10.533 \pm 1.528$ $\mu \mathrm{g} . / \mathrm{g}$.) of control mothers than in muscles (8.333 \pm 0.528 $\mu \mathrm{g} . / \mathrm{g}$ ). Mothers exposed to different concentrations of NP $(15,30 \mu \mathrm{g} / \mathrm{L})$ showed higher concentrations of NP in both livers and muscles than in those of the control groups with increasing exposure due to bioaccumulation.

2. concentrations of NP are higher in the livers $(12.333 \pm 1.528$ $\mu \mathrm{g} . / \mathrm{g}$.) of control larvae than in muscles $(7.333 \pm 2.517$ $\mu \mathrm{g} . / \mathrm{g})$. Larvae exposed to different concentrations of NP $(15,30 \mu \mathrm{g} / \mathrm{L})$ showed higher concentrations of NP in both livers and muscles than in those of control groups with increasing exposure due to bioaccumulation. This is quite evident in the treated mother groups.

Morphological examination

The numbers of dead fish throughout the experiments were within a normal range and all of them were healthy.

TABLE 1

Concentration of 4-NPnonylephenol in water $(\mu \mathrm{g} / \mathrm{L})$ and sediments $(\mu \mathrm{g} / \mathrm{g})$ of Abhur site.

\begin{tabular}{cccc}
\hline Site & & Water & Sediments \\
\hline Abhur site & Mean \pm S.D & $4.65 \pm 2.61$ & $32.33 \pm 3.21$ \\
\hline
\end{tabular}


TABLE 2

Bioaccumulation of 4-NP( $\mu \mathrm{g} / \mathrm{g}$. $)$ in liver and muscles of Fish larvae From untreated and treated mothers with different concentration of 4-NP.

\begin{tabular}{|c|c|c|c|c|}
\hline Groups & concentration of $4-\mathrm{NP}$ in water $\mathrm{Mg} / \mathrm{L}$ & & liver & Muscles \\
\hline \multirow[t]{2}{*}{ Treated mother } & 15 & Mean \pm S.D & $37.00 \pm 9.786$ & $27.600 \pm 5.598$ \\
\hline & 30 & Mean \pm S.D & $43.00 \pm 8.600$ & $32.300 \pm 6.780$ \\
\hline \multirow[t]{2}{*}{ Larvae from treated mother } & 15 & Mean \pm S.D & $44.33 \pm 10.600$ & $38.000 \pm 6.080$ \\
\hline & 30 & Mean \pm S.D & $51.667 \pm 9.127$ & $52.333 \pm 6.506$ \\
\hline Standard mother & 4.65 & Mean \pm S.D & $10.533 \pm 1.528$ & $8.333 \pm 0.528$ \\
\hline Larvae from untreated mothers & 15 & Mean \pm S.D & $34.333 \pm 9.661$ & $25.000 \pm 5.568$ \\
\hline Larvae reared at standard water & 4.65 & Mean \pm S.D & $12.333 \pm 1.528$ & $7.333 \pm 2.517$ \\
\hline
\end{tabular}

Histological examination of liver

Maternal control specimens

Histological examination of liver sections revealed a normal architecture according to sea fish (Roberts, 1978). Although this was a control group, some pathological changes were observed, such as light staining and loss of the hexagonal structure of liver cells. The rest of the cells were arranged in a normal hexagonal pattern with deeply stained central nuclei in acidophilic cytoplasm. The cells were separated by blood sinusoids from a central vein (Fig. 1).

1. First sub-group (control larvae)

Stained sections showed central vein with radiated hepatocytes, separated by sinusoid with Kupffer cells (Fig. 2).

2. Second sub-group (treated larvae from non-treated mothers)

Tissue section examinations of the group treated with low concentrations of NP $(15 \mu \mathrm{g} / \mathrm{L})$ showed disruption of liver architecture. In spite of the presence of normal cells, the majority showed lyses, loss of nuclei, the presence of vacuolar cells and stagnation of blood in sinusoids (Fig. 3).

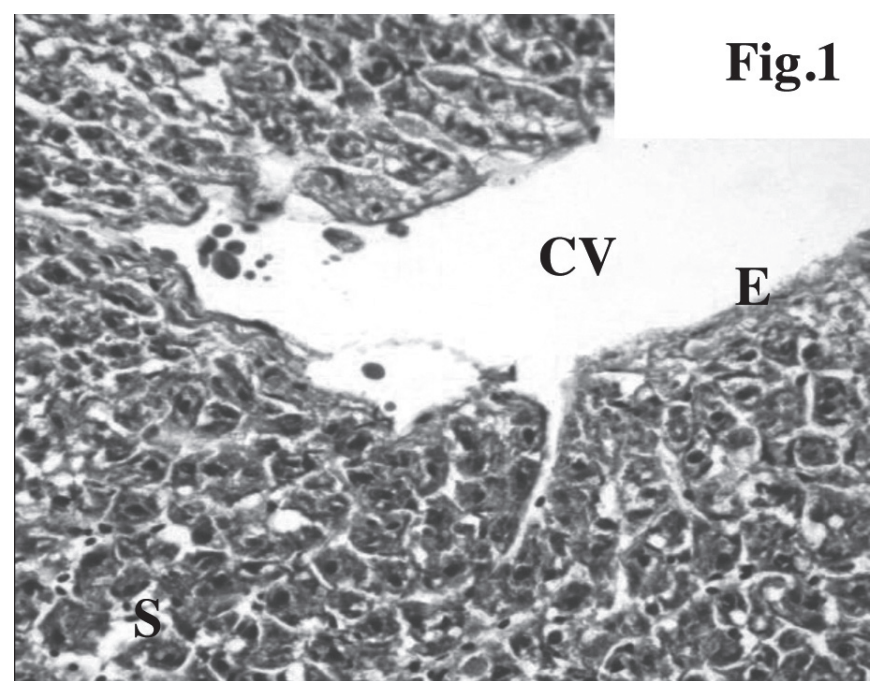

Fig. 1: Light micrograph for typical structure of maternal nontreated liver showing: central vein (CV) lined with endothelial cells (E) and sinusoid with Kupffer cells(S).

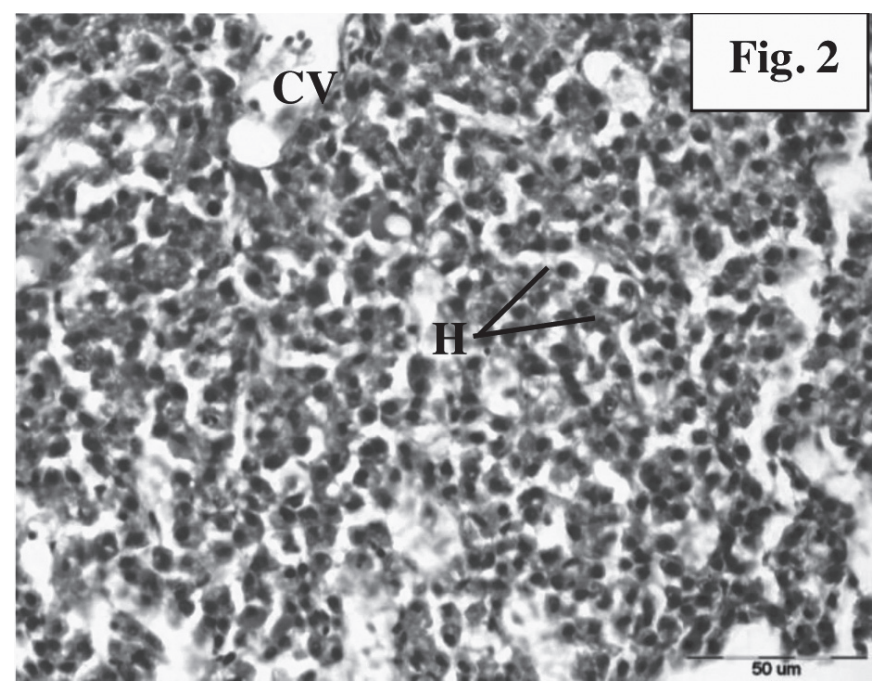

Fig. 2: Light micrograph for typical structure of standard liver of larva showing: central vein (CV) with radiated hepatocytes (H) separated by sinusoid with Kupffer cells(S).

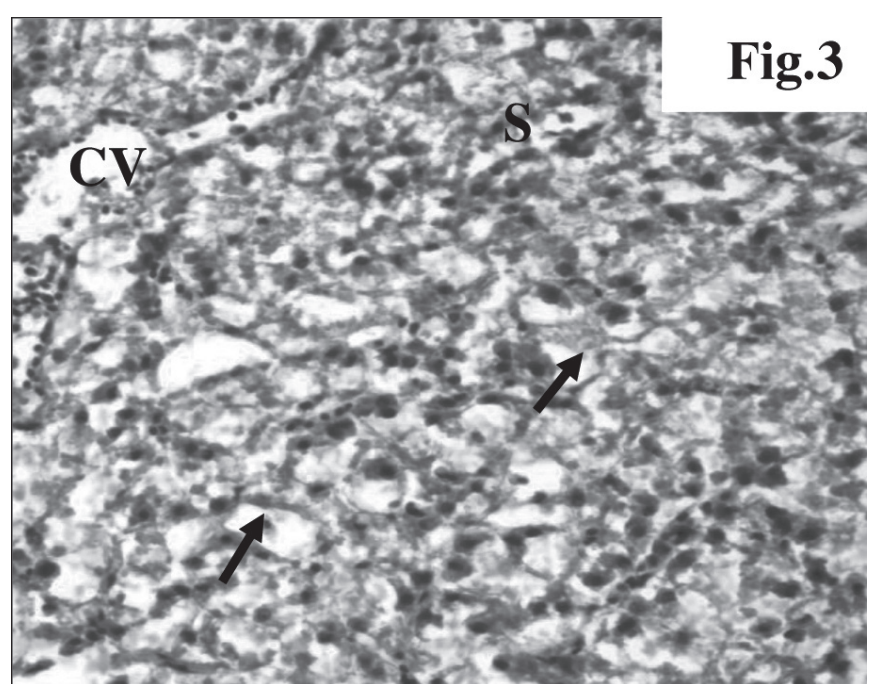

Fig. 3: Light micrograph of treated larvae liver from non-treated mother (15 mg NP/L) showing: congestion of both central vein (CV) and sinusoid(S) with vacuolar degeneration of hepatocytes (arrows). 
3. Third sub-group (treated larvae from non-treated mothers)

The changes were more marked in tissues exposed to higher concentrations of NP $(30 \mu \mathrm{g} / \mathrm{L})$ where sections showed dilated blood vessels, loss of the hexagonal architecture of the liver, presence of fat globules, eccentric nuclei in cells and vacuolated cytoplasm. Other fields showed more damage represented by an increase in the number of cells, decreased affinity to eosin due to vacuolated cytoplasm, deep staining of pyknotic nuclei and the presence of clapped sinusoids full of stagnant blood (Fig. 4).

Treated maternal specimen

1. First sub-group (treated mothers and larvae)

Examination of the sections from the mothers of the group exposed to a lower concentration of NP revealed more loss of the ribbon-shaped structure, the presence of areas with lyses and some staining, but the rest maintained the normal hexagonal architecture, with deeply stained and degenerated nuclei in cytoplasm, and the central vein and sinusoids filled with stained fluid (Fig. 5). In the treated larvae from treated mothers, there are also some vessel abnormalities, such as a dilated central artery, ruptured vessel walls, dilated sinusoids, increased number of kuppfer cells, increased fat globules in cells and the presence of deeply stained degenerated nuclei (Fig. 6).

2. Second sub-group (treated mother and larvae from treated mothers)

The exposure of mothers to the higher concentration of NP resulted in changes that ranged from severe to moderate, represented by the presence of hemorrhaging in the central vein, increased wall thickness, lyses of cytoplasm in the majority of cells, loss of cell boundaries,

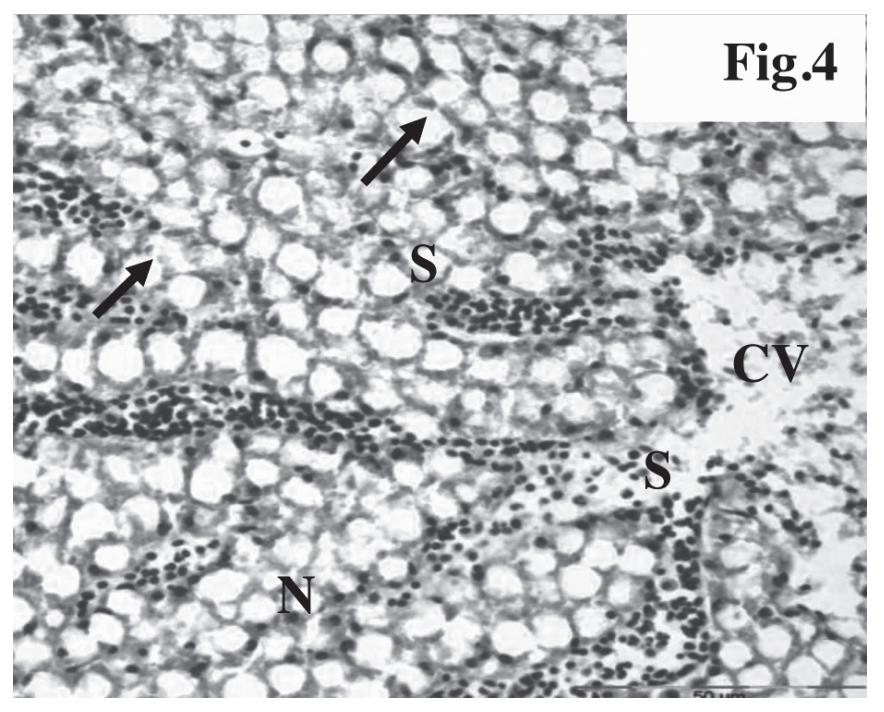

Fig. 4: Light micrograph of treated liver from non-treated mother (30 mg NP/L) showing: hepatocytes with lipid droplets (arrow) and marginal nuclei. Not, congestion and dilatation of both sinusoids (S) and central vein(CV). dilated sinusoids, the vacuolated hepatic cord separated by dilated blood vessels that had ruptured endothelium, darkly stained cytoplasm and deeply stained nuclei (Fig. 7). The treated larvae from treated mothers showed loss of liver architecture, increased number of cells containing bare nuclei, increased fat content and the presence of short compressed unconnected sinusoids (Fig. 8).

\section{DISCUSSION}

Water and sediment analysis

The results showed that sediments contained high concentrations of NP compared to water in the selected zone

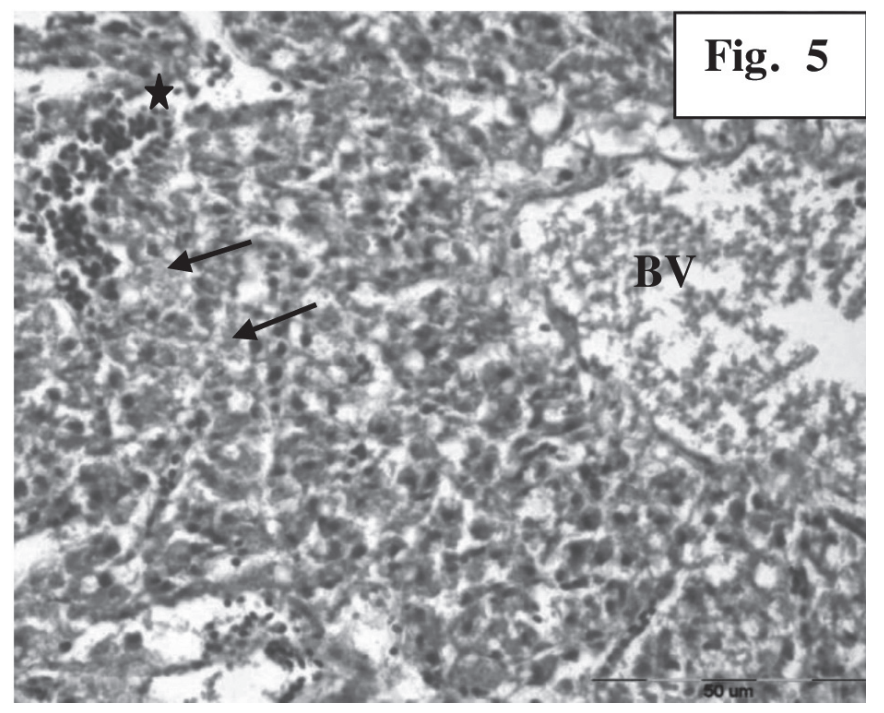

Fig. 5: Light micrograph of treated larvae liver from treated mother (15 mg NP/L) showing: Disturbance of hepatic architecture. Note, dilated and congested blood vessel (BV),stasis of red blood cells (stare) and necrotic area (arrows) (H\&E x 40).

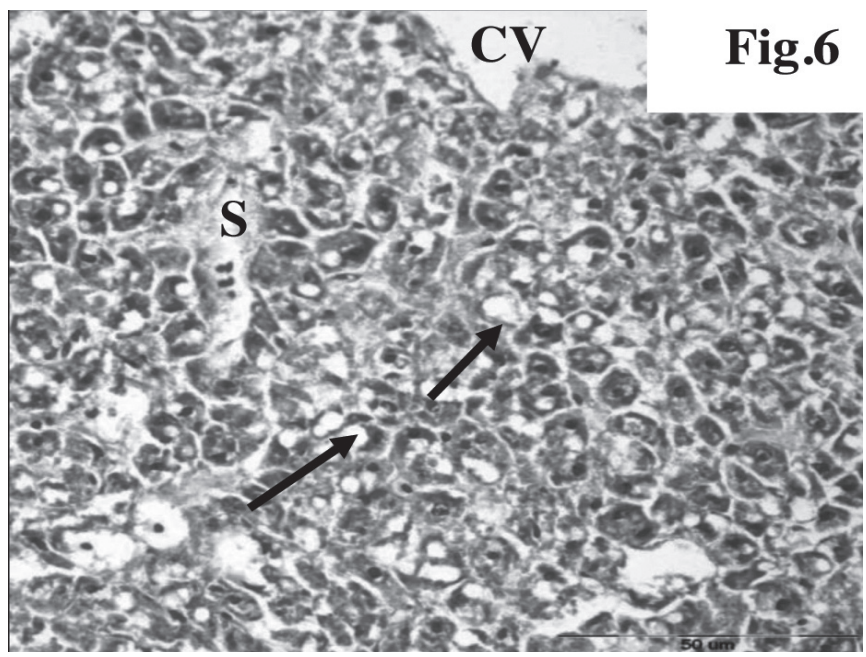

Fig. 6: Light micrograph of treated larvae liver from treated mother (15 mg NP/L) showing: dilated sinusoids (S) and central vein(CV). Note hepatocytes with variable sized of fat vacuoles (arrows). 
and this was supported by previous studies that demonstrated the hydrophobic nature of NP compounds, their strong affinity to precipitate with non-soluble molecules, and that their final degradation with $\mathrm{CO} 2$ and water is very slow due to the slow breakdown of the phenol ring (Talmage, 1994; Nimord and Benson, 1996). Consequently fish living in this zone that are exposed to estrogenic alkylphenols, either directly from sediments or indirectly by feeding on the invertebrates living on these surfaces, will be seriously affected. In this work, the concentration of NP compounds in many specimens obtained from sediments in areas close to sewage outlets and areas close to industrial effluents reached $(32.33 \pm 3.21 \mu \mathrm{g} / \mathrm{g}$.), which contrasts with low concentrations

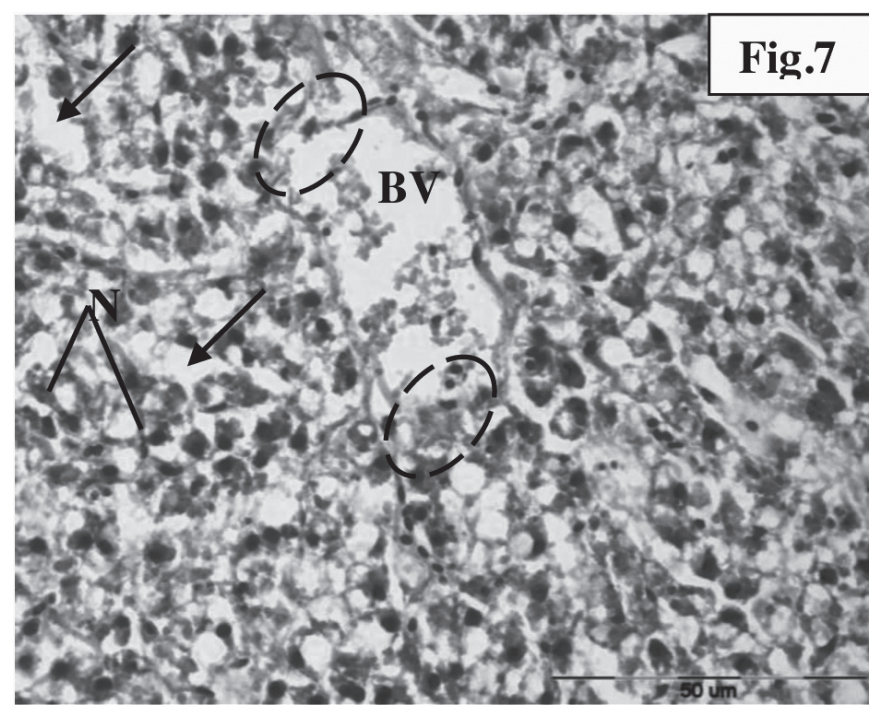

Fig. 7: Light micrograph of liver from treated mother $(30 \mathrm{mg}$ NP/L) showing: the vacuolated hepatic cord separated by dilated blood vessels (arrows) which have ruptured endothelium (dashedline ). Note, pyknotic nuclei (N). (H\&E x40).

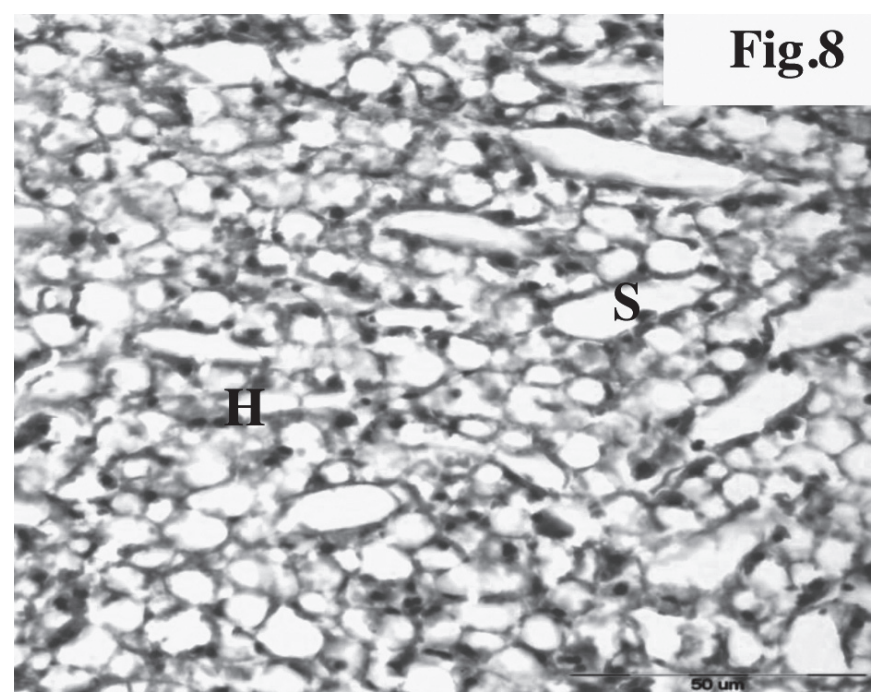

Fig. 8: Light micrograph of treated larvae liver from treated mother (30 mg NP/L) showing: marginal nuclei of atrophied hepatocytes (H) with fatty tissue appearance. Not, short and closed sinusoids (S) (H\&E-X400). that did not exceed $12.4 \mathrm{mg} / \mathrm{kg}$ (Hale et al., 2000), indicating that NP compounds exist among a mixture of other compounds, such as octyl and disulphonic, in spite of their low concentrations (Bennie, 1999).

\section{Concentration of 4-NP in tissues}

Low concentrations of NP were found in muscles $(7.333 \pm 2.517$ $\mu \mathrm{g} . / \mathrm{g})$ and liver $(12.333 \pm 1.528 \mu \mathrm{g} . / \mathrm{g}$.) of control larvae fish and in control mothers in muscle $(8.333 \pm 0.528)$ and in liver $(10.533 \pm 1.528)$. There was a relative increase in concentrations in tissues among young fish from untreated mothers with the increase in exposure from 15 to $30 \mathrm{mg} / \mathrm{L}$. There was also a marked increase in concentrations in tissues of fish from treated mothers, with both the lower and higher concentrations. This reflects the bioaccumulation of NP in fish tissues through the main sources, namely gills and the alimentary canal. Consequently these pollutants reach liver tissues through the blood (Roberts, 1978). It was clear from our results that the liver has more bioaccumulation than the muscles because of it role in storage, detoxification and regulation of all metabolic processes (Elrayis,1989).

This study showed that NP concentrations increased in the tissues of the young of mothers previously exposed, indicating long-term vertical transmission. Studies in the UK have demonstrated the presence in sewage systems of high concentrations of natural estrogenic compounds like estrone, 17-B-estradiol and synthetic estrogen from contraceptive pills made with ethinyl estradiol. The concentrations were high enough to stimulate vitellogenin. Many highly lipophilic and strongly adsorptive endocrine disrupting chemicals accumulate in sediments and tissue, increasing the probability that fish are exposed to the additive effects of other estrogenic compounds, which contributes to the overall contamination of the water environment (Virtanen, 1986).

\section{Histological examination}

Histological examination of tissues from fish exposed to different doses of NP compounds during pregnancy, development and maturity showed severe and variable affects, which increased with increased duration of exposure at the lower and higher concentrations. These results agree with previous studies that have demonstrated acute inflammatory edema and activation of kuppfer cells in cases of poisoning, especially with pesticides (Lutty et al., 2000). Burkitt et al. (1996) related these inflammatory changes to the immune reaction of the body to harm induced by chemicals and to infection by viruses and parasites that affected cells and tissues. The cellular edema of macrophages is considered a marker of chronic inflammation, where lymphocytes are responsible for the production of antitoxins and cell healing (Curran, 1996). Sileo et al. (2004) explained that the formation of cytoplasmic vacuoles in liver tissues of exposed birds living in water environment was due to acute intoxication by zinc and lead, which also appeared in the present tissue abnormalities. Mollendroff (1973) discovered that the formation of vacuoles is a defense mechanism by which the cell collects harmful and degraded substances to prevent interference with its viable activity. Burkitt et al. (1996) noted that interference with fatty acid metabolism leads to accumulation of neutral fat, resulting in equal-edged, and non- 
membranous empty vacuoles. The neutral fat is dissolved by organic solvents during tissue preparation, leaving unstained empty vacuoles. Fatty infiltration can accompany hydropic degeneration, which appears as faintly stained vacuoles.

Examination of tissue sections treated with low doses showed that the liver cells maintain their ribbon-shaped structure, normal arrangement around the central vein, and normal content of cytoplasm and nuclei. Accumulation of fat droplets of different sizes in different cells was also observed. In addition, many dispersed cells with degenerated nuclei were observed, deeply stained with eosin. These cells separate from the rest due to dilation of intercellular spaces initiating cell necrosis. Studies have shown that the fatty infiltration and vacuolar degeneration are due to different contaminants. Khadre (1992) observed that exposure of T. Zilli fish to heavy metals resulted in swelling of liver cells due to accumulation of cytoplasmic vacuoles, nuclear atrophy and lyses of plasma membrane. Other studies have shown that exposure of Siganus rivulates fish to heavy metals results in abnormal liver architecture, fullness of cells with fat and their necrosis (Abdelaziz et al., 2006). Fabacher and Chambers (1971) determined that the amount of fat in Gambusia sp. fish is directly proportionate to their tolerance to insecticide DDT as fat gave them protection from toxins (Cheville, 1988). The effects on liver tissue increased with a higher doses and longer exposure, with the spread of necrotic cells in liver parenchyma. These cells can be distinguished from neighboring cells by their ribbon shape reflecting focal lysis. The cells degenerated and transformed to eosinic masses with no nuclei or atrophied and deeply stained nuclei. The other sections showed abnormalities, such as dilation of both sinusoids, central and portal veins and RBCs accumulation. There was a disturbance of liver architecture with many spaces that made the liver cells indistinguishable. This was probably due to loss of structural proteins (Burkitt et al., 1996). Kaptaner and Unal (2010) investigated that NP-dependent hepatotoxicity was causally related to the increase in apoptosis where NP $\left(200 \mu \mathrm{g} \mathrm{L}^{-1}\right)$ caused significant increases in the extent of apoptosis in liver .

It is worth noting that the harmful effects on tissues, which varied in severity, were present in untreated fish reared in natural water and treated fish exposed to NP, indicating water pollution. Although this pollution was not lethal, its effect will be reflected in economic development and human reproduction.

\section{ACKNOWLEDGMENT}

I am very grateful to Dr. Awatef Ali (Zoology DepartmentCollege of Science - Alexandria University) for her continuous encouragement whilst completing this manuscript.

\section{REFERENCES}

ABDELAZIZ SH, ELGHAZALY N, BINDOHAISH GA (2006) Effect of pollutants in coastal water of Jeddah on2- the histological structure of liver of the fish Siganus rivulatus. Saudi Arabia. Egyption Journal of Aguatic research 32: 316-333.

AHEL M, GIGER W (1993) Partitioning of alkylphenols and alkylphenolethoxylates between water and organic solvents. Chemosphere 26:1471-1478.

ASENZO G, CORCIA A, GENTILI A, MANCINI R, MASTROPASQUA R, NAZ-ZARI M, SAMPERI R, (2003) Fate of natural estrogen conjugates in municipal sewage transport and treatment facilities. Sci. Total Environ 302: 199-209.

BENNIE DT (1999) Review of the environmental occurrence of alkylphenols and alkylphenolethoxylates. Water Qual Res. J. Canada 34:79-122.

BINDOHAISH G (2008) Effects of environmental pollution with alkylphenol (4-Nonyl phenol) on reproduction of Tilapia, Oreochromus spilurs (Teleosts). Egyption Journal of Aquatic research 34:336-355.

BURKITT HG, STEVENS A, LOWE JS, YOUNG B (1996) Wheater's basic histopathology. International Student Edition. New York 299.pp: 88-93.

CHEVILLE NF (1988) Introduction to veterinary pathology. Iowa state University press. Ames, IA, pp: 537-540.

ELRAYIS OA (1989) Distribution of some heavy metals in sediments, water and different trophic levels from Jeddah coast, REDSEA. J. K. A. U.; Mar.sci 3:33-45.

FABACHER DL,CHAMBERS H (1971) A possible mechanism of insecticide resistance in mosquito-fish, Bull. Environ. Contam. Toxicol 6: 372-376.

GIMENO S, KOMEN H, JOBLING S, SUMPTER J, BOWMER T (1998) Demasculinisation of sexually mature male common carp, Cyprinus carpio, exposed to 4-tert-pentylphenol during spermatogenesis. Aquat Toxicol 43:93-109.

HALE RC, SMITH C L, DE FUR P O, HARVEY E , BUSH EO, LA GUARDIA M J,VADAS GG (2000) Nonylphenols in sediments and effluents associated with diverse waste water outfalls. Environ. Toxicol. Chem 19:946-952.

HARRIES JE, RUNNALLS T, HILL E, HARRIS CA, MADDIX S, SUMPTER JP, TYLER CR (2000) Development of a reproductive performance test for endocrine disrupting chemicals using Pair-Breeding fathead minnows (Pimephales promelas). Environ. Sci. Technol. 34:3003-3011.

JESSICA D, ROBERT M, FREDERIC S, ARNAUD B, DELPHINE L, JEANPIERRE T, PATERICK K (2006) Do sewage treatment plant discharges substantially impair fish reproduction in polluted rivers? Sci. Total Environ.

JOHNSON AC, AERNI HR, GERRITSEN A, GIBERT M, GIGER W, HYLLAND K, JURGENS M, NAKARI T, PICKERING A, SUTER M J F, SVENSON A, WETTSTEIN FE (2005) Comparing steroid estrogen, and nonylphenol content across a range of European sewage plants with different treatment and management practices. Water Res 39: 47-58.

KAPTANER B, ÜNAL G (2010) Effects of 17-ethynylestradiol and nonylphenol on liver and gonadal apoptosis and histopathology in Chalcalburnus tarichi. Inc. Environ Toxicol 3:33-41.

KHADRE SE (1992) Cytological and cytochemical studies on the liver of Tilapia zilli surviving in lake maruit.Proceed of $2^{\text {nd }}$ inter.Conf.Environ. Prot.Is a must 4:152-158.

KIME DE (1998) Endocrine Disruption in Fish.Kluwer Academic Publishers, Boston, MA.

LUTY S, LATUSZYNSKA J,OBUCHOWSKA P D,TOKAESKA M et.al. (2000) Subacute toxicity of orally applied alpha- cypermenthrin in swiss mice. Am. Agric. Environ. Med 7: 33-41.

MA T, WAN X, HUANG Q, WANG Z, LIU J (2005) Biomarker responses and reproductive toxicity of the effluent from a chinese large sewage treatment plant in Japanese medaka (Oryzias Latipes). Chemo-Sphere 59: 281-288.

MALTHIESSEN P, ALLEN Y T, ALLCHIN C R, FEIST S W, KIRBY M F, SCOTT A P, THAIN J E, THOMAS KV (1998) Estrogenic endocrine disruption in flounder (Platichthys Flesus) from United Kingdom estuarine and marine waters; Technical Report No. 107; The U. K. center for Environment Fisheries \& Aquaculture science (CEFAS). Science Series; Lowest oft. Pp. 48.

MOLLENDROFF A (1973) cytology and cell physiology $3^{\text {rd }}$ ed. New York. Academic press. pp: 50-55.

NIMROD AC, BENSON WH (1996) Environmental estrogenic effects of alkylphenol ethoxylates. Crit Rev Toxicol 26:335-364.

ROBERTS RJ (1978) Fish pathology. Bailliere tindall, London, pp. 489.

SILEO L, BEYER WN, MATEO R (2004) Pancreatitis in wild zinc-poisoned waterfowl. Avian pathology 32: 655-660.

TALMAGE SS (1994) Environmental and human safety of major surfactants; Lewis Publishers: Boca Raton. pp: 45-50.

TYLER CR, JOBLING S, SUMPTER JP (1998) Endocrine disruption in wildlife: a critical review of the evidence. Crit. Rev Toxicol 28: 319-361.

VIRTANEN MT (1986) Histological and Ultrastructural changes in the gills of Poecilia reticulates induced by an organochlorine pesticide. Jepto 7:73-86.

YING G, KOOKANA RS, RU Y (2002) Occurrence and fate of hormone steroids in the environment. Environ. Int 28: 545-551. 